\title{
PECULIARITIES OF GROWING AND ANALYSIS OF FEEDING PROGRAMS TURKEYS
}

\begin{abstract}
According to the literature poultry occupies a leading position in the structure of the meat market. The leader in poultry farming is the production of broiler meat both in the world and in Ukraine. However, in recent years the interest in growing turkeys and turkey meat production increased sharply, as a lucrative business and an alternative to pork and beef. It is estimated that in the world turkey's meat consumption has increased from 1,5 million tones to 5,5 million tones in recent years Israel is the world leader in annual consumption of turkey meat (13.1 kg per head), and USA is the world leader in production of turkey meat (42\% of total production). In 2017 turkey meat production in the world amounted to 6.4 million tones, only 34 thousand tones were produced in Ukraine of them.

The main characteristics of the two turkey breeds are given. They are the bronze-breasted and white-breasted breeds. Almost all modern turkey industrial crosses have come from them. All high-productive turkey crosses are divided into types depending on the weight: light, medium, medium heavy, heavy. Each has its own purpose for use.

As a result of the analysis of the literature data, the production indicators for modern turkey crosses and norms of the content of nutrients and biologically active substances in feeds for turkeys of heavy and medium types were generalized.

We developed turkey feeding programs based on years of experience, scientific achievements in the industry and fruitful collaboration with feed manufacturers. There are several periods during the life of the turkeys: the period of rearing, pre-laying (rearing of the repair young turkeys) and productive. It is established that young turkeys of various purposes are fed the same rations for up to 17 weeks. According to the developed turkey feeding program the period of rearing consists of 3 phases, during which use starter (1 - 4 weeks for heavy type turkeys and 1 - 8 weeks for medium type turkeys), grower (5 - 13 weeks for heavy type turkeys and 9 - 13 weeks for medium type turkeys) and finisher (14-17 weeks) feed. The pre-laying diet is fed from 18 to 30 weeks to repair young turkeys, and productive diet is fed from 31 weeks.
\end{abstract}

Key words: turkeys, feeding technology, feeding program, feed nutrition requirements for turkeys, turkey breeds and crosses.

\section{Introduction}

It is not the first year that the global structure of the meat market is changing. Poultry farming occupies a leading position. In the world the share of poultry products will increase to $40 \%$ by 2030 according to the Poultry Union of Ukraine. This is due to the growing demand for meat products. The manufacturers must produce high quality and safe products, using all modern science and technology in tough conditions of competition, declining fertile land, limiting resources and increasing the world's population.

The leader in poultry farming is the production of broiler meat, both in the world and in Ukraine. However, in recent years the interest in growing turkeys and turkey meat production increased sharply, as a lucrative business and an alternative to pork and beef. Every year in our country the investment attractiveness of this business grows by $20-30 \%$, its profitability is $20-25 \%$ [ $1-3]$.

Dietary turkey meat is easy to digest. It is rich in protein, but has a low fat content. Dietary turkey meat contains B vitamins, a lot of phosphorus, iron, potassium, magnesium. It is a source of zinc and promotes proper absorption of fats, proteins and carbohydrates. Turkey meat provides the human body with the necessary amino acids and has a positive effect on health, in particular - on the state of hematopoietic organs and bones. The spread of organic food consumption and proper nutrition explains the increased interest in turkey meat. In addition, turkey meat has no religious prohibitions, unlike pork and beef. Turkey eggs are nutritious, tasty and 2 times more than chicken eggs in size. They can be stored for a long time due to the dense and durable shell and subshell $[4,5]$.
It is established that the feed conversion rate for turkeys is about $3 \mathrm{~kg} / \mathrm{kg}$ and the yield of pure meat reaches $80 \%$. These can be achieved without the use of hormonal drugs and growth promoters. By comparison, the feed conversion rate for piglets is $4,5 \mathrm{~kg} / \mathrm{kg}$ and the yield of pure meat is no more than $65 \%$.

In the world turkey's meat consumption has increased from 1,5 million tones to 5,5 million tones in recent years. Global consumption of turkey meat is expected to increase to 6,7 million tones by 2025 . Fig. 1 shows the world annual consumption of turkey meat per head [1 - 3].

The turkey meat consumption is directly dependent on the income level of the population, that's why it is higher in countries with a high standard of living. In addition, consumption increases significantly during Christmas, Easter, and Thanksgiving day.

In 2017 turkey meat production in the world amounted to 6.4 million tones. Fig. 2 shows the structure

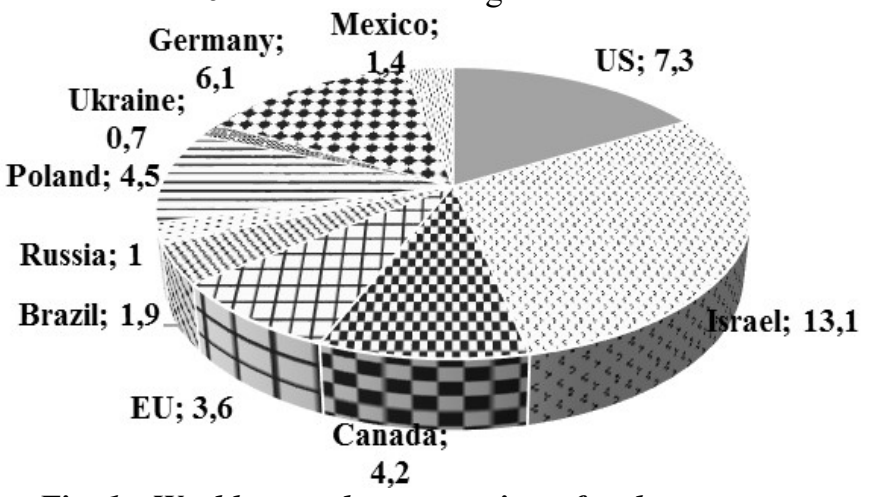

Fig. 1 - World annual consumption of turkey meat per head 


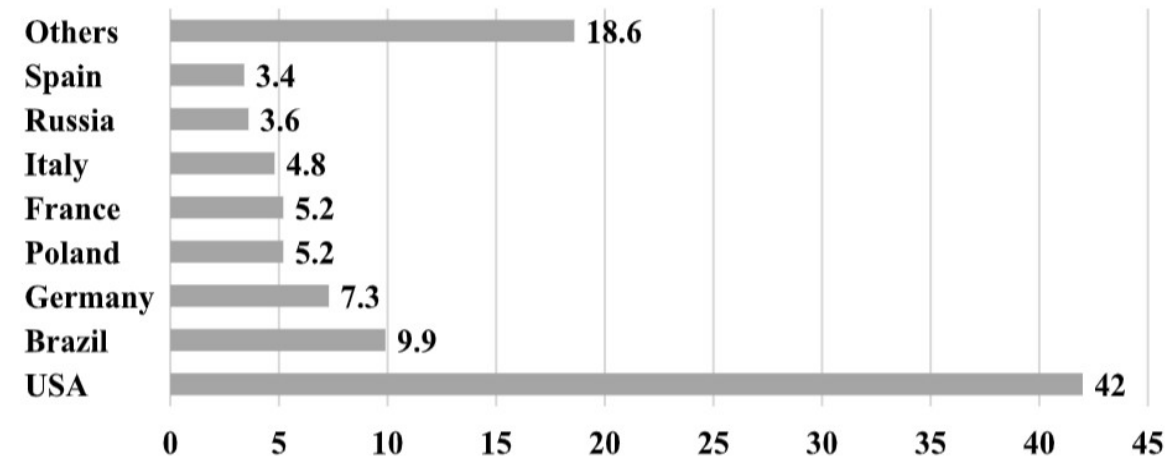

Mass fraction in the turkey meat production, $\%$
Broilers are grown for 6-8 weeks depending on the required final live weight. Turkeys are grown for at least 16 weeks.

As a result of productive breeding work, many breeds of turkeys have been created. Bronze broad-breasted and white broad-breasted breeds are the main breeds of turkeys. These breeds of turkeys are bred in the USA. However, modern industrial turkey meat production is based not on purebred poultry but on highly productive turkey crosses whose hybrid forms are characterized by the effect of heterosis.

In poultry crosses are commonly referred to as the combination of combined lines of birds and their hybrids. They are obtained according to certain schemes of crossing with different qualities or features. They produce heterosis on one or more of the offspring.

Heterosis means the superiority of offspring on one or another trait (growth rate, meat quality, feed conversion, etc.) over indicators of better parental forms over indicators of better parental forms.

Almost all modern industrial crosses of turkeys went from them. Most of the highly productive crosses have been created on the basis of the white broadbreasted breed. High productive crosses are divided into types: light (weight of adult females $5-8 \mathrm{~kg}$, weight of adult males up to $18 \mathrm{~kg}$ ), medium (respectively $8-10$ and up to $25 \mathrm{~kg}$ ), medium heavy (9 - 11 and up to 30 ) and heavy (10 - 13 and up to $40 \mathrm{~kg})$. Crosses of light and medium types are intended for production and realization of whole carcasses, that is impractical at this development stage of turkey production. Today carcasses divided into parts are in demand on the market, which are received from the crosses of medium heavy and heavy types. The advantages of light crosses are the best reproductive qualities of turkeys, which means lower cost of daily turkeys, slightly lower requirements for cultivation, keeping and feeding. The advantages of heavier crosses are rapid growth, lower feed costs per $1 \mathrm{~kg}$ of live weight gain, the ability to produce large carcasses suitable for processing, an increase of meat yield during slaughter by $1-3 \%$. Modern turkey crosses are grown according to intensive (turkeys are characterized by intensive growth and low feed conversion) and extensive technologies. Intensive technologies involve the use of high-quality mixed feeds that fully satisfy the needs of poultry in nutrient and biologically active substances. Recently there has been a demand for turkey meat, which was grown using extensive technology. This poultry is characterized by high feed conversion, but for its fattening organic and environmentally friendly feeds are used $[6,7]$. 
Table 1 - Characteristics of turkeys crosses

\begin{tabular}{|c|c|c|c|c|c|c|c|c|c|c|c|c|c|}
\hline \multirow[t]{2}{*}{ Indicators } & \multirow[b]{2}{*}{$\begin{array}{l}\text { «Harkiv } \\
\text { s'kij»» }\end{array}$} & \multicolumn{5}{|c|}{ «"British United Turkeys Ltd» } & \multicolumn{4}{|c|}{ «Nicholas Turkeys Ltd» } & \multicolumn{3}{|c|}{ «Hybrid Turkeys Ltd» } \\
\hline & & $\begin{array}{l}\text { B.U.T. } \\
-8 .\end{array}$ & $\begin{array}{l}\text { B.U.T } \\
.-10 .\end{array}$ & Big-6 & Big-7 & Big-9 & $\begin{array}{c}\text { Nicholas } \\
300 \times 85\end{array}$ & $\begin{array}{c}\text { Nicholas } \\
300 \times 88\end{array}$ & $\begin{array}{c}\text { Nicholas } \\
700 \times 85\end{array}$ & $\begin{array}{l}\text { Nicholas } \\
700 \times 88\end{array}$ & $\begin{array}{l}\text { Hybrid } \\
\text { Gra-de } \\
\text { Maker }\end{array}$ & $\begin{array}{c}\text { Hybrid } \\
\text { Conventer }\end{array}$ & Hybrid XL \\
\hline Cross type & Light & \multicolumn{2}{|c|}{ Medium heavy } & \multicolumn{3}{|c|}{ Heavy } & \multicolumn{2}{|c|}{ Medium heavy } & \multicolumn{2}{|c|}{ Heavy } & Light & Medium & Heavy \\
\hline Products type for sale & & \multicolumn{2}{|c|}{$\begin{array}{c}\text { Whole carcasses } \\
\text { and divided into } \\
\text { parts }\end{array}$} & \multicolumn{3}{|c|}{$\begin{array}{l}\text { Carcasses are divided into } \\
\text { parts and for processing }\end{array}$} & \multicolumn{2}{|c|}{$\begin{array}{l}\text { Whole carcasses and } \\
\text { divided into parts }\end{array}$} & \multicolumn{2}{|c|}{$\begin{array}{l}\text { Carcasses are divided } \\
\text { into parts and for } \\
\text { processing }\end{array}$} & \multicolumn{2}{|c|}{$\begin{array}{l}\text { Whole carcasses and } \\
\text { divided into parts }\end{array}$} & $\begin{array}{l}\text { Carcasses are di- } \\
\text { vided into parts } \\
\text { and for processing }\end{array}$ \\
\hline \multicolumn{14}{|c|}{ Weight of adult poultry of parent flock ( 29 weeks old), kg: } \\
\hline male & $17-20$ & 28,7 & 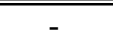 & 31,37 & 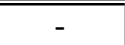 & 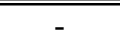 & 22,51 & 22,51 & 22,51 & 22,51 & 21,6 & 21,6 & 21,6 \\
\hline female & $8-9$ & 10,5 & 10,51 & 12,73 & 12,73 & 12,0 & 10,19 & 10,19 & 11,91 & 11,91 & 10,22 & 11,3 & 12,5 \\
\hline $\begin{array}{l}\text { Egg laying turkeys of parent flock } \\
\text { for } 26 \text { weeks, units eggs }\end{array}$ & $70-90$ & 132 & 132 & 118 & 111,5 & 118,2 & & & & & 126 & 109 & 100 \\
\hline \multicolumn{14}{|c|}{ Live weight of turkeys for intensive fattening $(\mathrm{kg})$ at age, weeks (males / females): } \\
\hline 12 & $\begin{array}{l}4,8 / \\
6,3 \\
\end{array}$ & $\begin{array}{l}6,03 / \\
8,31 \\
\end{array}$ & $\begin{array}{l}6,45 / \\
8,55 \\
\end{array}$ & $\begin{array}{l}7,32 / \\
9,88 \\
\end{array}$ & $\begin{array}{l}7,19 / \\
9,75 \\
\end{array}$ & $\begin{array}{l}6,99 / \\
9,43 \\
\end{array}$ & $\begin{array}{l}6,52 / \\
8,59 \\
\end{array}$ & $\begin{array}{l}6,67 / \\
8,81 \\
\end{array}$ & $\begin{array}{l}6,64 / \\
9,64 \\
\end{array}$ & $\begin{array}{l}6,79 / \\
9,86 \\
\end{array}$ & $\begin{array}{l}6,89 / \\
9,21 \\
\end{array}$ & $\begin{array}{l}7,47 / \\
9,93 \\
\end{array}$ & $\begin{array}{l}7,81 / \\
10,39 \\
\end{array}$ \\
\hline 16 & $6,7 / 9,7$ & $\begin{array}{l}8,49 / \\
12,59 \\
\end{array}$ & $\begin{array}{l}9,34 / \\
13,23 \\
\end{array}$ & $\begin{array}{c}10,74 / \\
15,3 \\
\end{array}$ & $\begin{array}{c}10,54 / \\
15,1 \\
\end{array}$ & $\begin{array}{l}10,25 / \\
14,66 \\
\end{array}$ & $\begin{array}{l}9,17 / \\
13,00 \\
\end{array}$ & $\begin{array}{l}9,39 / \\
13,24 \\
\end{array}$ & $\begin{array}{l}9,46 / \\
14,89 \\
\end{array}$ & $\begin{array}{l}9,68 / \\
15,23 \\
\end{array}$ & $\begin{array}{l}9,46 / \\
13,86 \\
\end{array}$ & $\begin{array}{l}10,32 / \\
15,12 \\
\end{array}$ & $\begin{array}{l}10,88 / \\
15,87 \\
\end{array}$ \\
\hline 18 & - & - & $\begin{array}{l}10,5 / \\
15,52 \\
\end{array}$ & $\begin{array}{c}12,22 / \\
17,9 \\
\end{array}$ & $\begin{array}{l}11,99 / \\
17,66 \\
\end{array}$ & $\begin{array}{l}11,66 / \\
17,08 \\
\end{array}$ & $\begin{array}{l}10,15 / \\
14,97 \\
\end{array}$ & $\begin{array}{l}10,39 / \\
15,37 \\
\end{array}$ & $\begin{array}{l}10,64 / \\
17,45 \\
\end{array}$ & $\begin{array}{l}10,88 / \\
17,85 \\
\end{array}$ & $\begin{array}{l}10,39 / \\
15,97 \\
\end{array}$ & $\begin{array}{l}11,38 / \\
17,58 \\
\end{array}$ & $\begin{array}{l}12,00 / \\
18,48 \\
\end{array}$ \\
\hline 20 & $\begin{array}{l}8,1 / \\
12,8 \\
\end{array}$ & $\begin{array}{l}10,05 / \\
16,65 \\
\end{array}$ & $\begin{array}{c}* / \\
17,77 \\
\end{array}$ & $\begin{array}{l}13,49 / \\
20,39 \\
\end{array}$ & $\begin{array}{l}13,23 / \\
20,12 \\
\end{array}$ & $\begin{array}{c}12,87 \\
/ 19,45 \\
\end{array}$ & $\begin{array}{c}-/ \\
16,7 \\
\end{array}$ & $\begin{array}{c}-/ \\
17,15 \\
\end{array}$ & $\begin{array}{l}11,63 / \\
19,84 \\
\end{array}$ & $\begin{array}{l}11,90 / \\
20,29 \\
\end{array}$ & $\begin{array}{c}-/ \\
17,86 \\
\end{array}$ & $\begin{array}{l}12,25 / \\
19,98 \\
\end{array}$ & $\begin{array}{l}12,96 / \\
20,91 \\
\end{array}$ \\
\hline 22 & & & & & & & $\begin{array}{c}-/ \\
18,15 \\
\end{array}$ & $\begin{array}{c}-/ \\
18,65 \\
\end{array}$ & $\begin{array}{l}12,36 / \\
21,95 \\
\end{array}$ & $\begin{array}{l}12,64 / \\
22,45 \\
\end{array}$ & - & $\begin{array}{c}-/ \\
21,98 \\
\end{array}$ & $\begin{array}{c}-/ \\
23,14 \\
\end{array}$ \\
\hline 24 & $-/ 15,4$ & $* / 20,49$ & - & $* / 25,15$ & $* / 24,90$ & $-/ 24,00$ & & & & & & & \\
\hline \multicolumn{14}{|c|}{ Feed conversion of turkeys (kg / kg) by age, weeks (males / females): } \\
\hline 12 & $\begin{array}{l}2,1 / \\
2,05\end{array}$ & $\begin{array}{l}2,12 / \\
2,09 \\
\end{array}$ & $\begin{array}{c}2,07 / \\
1,88\end{array}$ & $\begin{array}{l}2,09 / \\
1,92\end{array}$ & $\begin{array}{c}2,07 / \\
1,87\end{array}$ & $\begin{array}{l}2,09 / \\
1,92\end{array}$ & $\begin{array}{c}2,09 / \\
1,95\end{array}$ & $\begin{array}{l}2,09 / \\
1,95\end{array}$ & $\begin{array}{l}1,96 / \\
1,83\end{array}$ & $\begin{array}{l}1,96 / \\
1,83 \\
\end{array}$ & $\begin{array}{l}1,93 / \\
1,84\end{array}$ & $\begin{array}{c}1,95 / \\
1,8\end{array}$ & $\begin{array}{l}1,94 / \\
1,79\end{array}$ \\
\hline 16 & $\begin{array}{l}2,6 / \\
2,5 \\
\end{array}$ & $\begin{array}{l}2,52 / \\
2,18 \\
\end{array}$ & $\begin{array}{l}2,45 / \\
2,14 \\
\end{array}$ & $\begin{array}{l}2,45 / \\
2,17 \\
\end{array}$ & $\begin{array}{l}2,41 / \\
2,11 \\
\end{array}$ & $\begin{array}{l}2,45 / \\
2,17 \\
\end{array}$ & $\begin{array}{l}2,43 / \\
2,38 \\
\end{array}$ & $\begin{array}{l}2,43 / \\
2,38 \\
\end{array}$ & $\begin{array}{l}2,39 / \\
2,16 \\
\end{array}$ & $\begin{array}{l}2,39 / \\
2,16 \\
\end{array}$ & $\begin{array}{l}2,43 / \\
2,22 \\
\end{array}$ & $\begin{array}{l}2,29 / \\
2,13 \\
\end{array}$ & $\begin{array}{l}2,29 / \\
2,12 \\
\end{array}$ \\
\hline 18 & & - & $\begin{array}{l}2,65 / \\
2,47\end{array}$ & $\begin{array}{l}2,65 / \\
2,32\end{array}$ & $\begin{array}{l}2,61 / \\
2,29\end{array}$ & $\begin{array}{l}2,64 / \\
2,32\end{array}$ & $\begin{array}{l}2,59 / \\
2,60\end{array}$ & $\begin{array}{l}2,59 / \\
2,60\end{array}$ & $\begin{array}{l}2,49 / \\
2,35\end{array}$ & $\begin{array}{l}2,49 / \\
2,35\end{array}$ & $\begin{array}{l}2,67 / \\
2,32\end{array}$ & $\begin{array}{l}2,49 / \\
2,30\end{array}$ & $\begin{array}{l}2,48 / \\
2,29\end{array}$ \\
\hline 20 & $\begin{array}{l}3,1 / \\
2,8 \\
\end{array}$ & $\begin{array}{l}3,02 / \\
2,51 \\
\end{array}$ & - & $\begin{array}{l}2,85 / \\
2,49 \\
\end{array}$ & $\begin{array}{c}2,81 / \\
2,46 \\
\end{array}$ & $\begin{array}{l}2,86 / \\
2,49 \\
\end{array}$ & $\begin{array}{c}-/ \\
2,85 \\
\end{array}$ & $\begin{array}{c}-/ \\
2,85 \\
\end{array}$ & $\begin{array}{l}2,69 / \\
2,54 \\
\end{array}$ & $\begin{array}{l}2,69 / \\
2,54 \\
\end{array}$ & $-/ 2,64$ & $\begin{array}{l}2,7 / \\
2,48 \\
\end{array}$ & $\begin{array}{c}2,68 / \\
2,46 \\
\end{array}$ \\
\hline 22 & & & & & & & $\begin{array}{c}-/ \\
3,12\end{array}$ & $\begin{array}{c}-/ \\
3,12 \\
\end{array}$ & $\begin{array}{l}2,90 / \\
2,75 \\
\end{array}$ & $\begin{array}{l}2,90 / \\
2,75 \\
\end{array}$ & - & $-/ 2,67$ & $-/ 2,67$ \\
\hline 24 & $-/ 3,1$ & $-/ 2,92$ & - & $-/ 2,91$ & $-/ 2,89$ & $-/ 2,92$ & & & & & & & \\
\hline
\end{tabular}




\section{Purpose and objectives of the analysis}

The purpose of the study is to gather information about the expediency and economic attractiveness of a turkey growing business, the characteristic of turkey breeds and crosses, their requirements in nutrients and biologically active substances in order to develop the own feeding program of turkey.

\section{Results and its discussion}

We have analyzed the production indicators for turkey crosses under optimal feeding and conditions of detention. The results of our work are presented in the table 1 .

We have summarized the norms of the content of nutrients and biologically active substances in mixed feeds for turkeys based on the analysis of literary sources of information (table 2, 3) $[4,8,9]$.

Feeding by phases is used in order to save feeds and to use them more rationally according to the requirements of the poultry organism at different stages of growth. Individual feeding programs are used in smallscale feeding to obtain passport productivity from a particular breed or cross, and a cost-effective result. The programs take into account the organizational, technological, economic conditions of farms, availability and quality of their own feeds, genetic capabilities of animals and other factors [10].

We developed turkey feeding programs based on years of experience, scientific achievements in the industry and fruitful collaboration with feed manufacturers (table 4).

Feeding turkeys of different age groups has its own peculiarities, which should be considered separately. There are several periods during the life of the turkeys: the period of rearing, pre-laying (rearing of the repair young turkeys) and productive. Young turkeys of various purposes are fed the same rations for up to 17 weeks.

The most responsible in maintaining and growing turkeys are the first 17 weeks of their lives. During this period good care and balanced feeding can guarantee that the young turkey will enter the poultry house able to fully realize its genetic potential. However, this fact is often underestimated. Errors made during this period can no longer be corrected. For this reason, poultry breeders often suffer significant losses associated with feed overfeeding, backlog in the weight, decreased egg production, deterioration in shell quality, diseases related with feeding errors, etc.

The period of rearing consists of 3 phases. In the first phase (1-4 weeks for heavy type turkeys and 1-8 weeks for medium type turkeys) starter feed is used. This period is characterized by intense development of the digestive system and the immune system. The primary purpose is to achieve the recommended daily average weight gain. During this period the bird needs to consume as much feed as possible, which must be of high quality and easily digestible (high in protein and energy).

Corn, wheat, soybean meal are used as raw materials. The introduction into the diet during this period of sunflower meal, barley, millet and other difficult-todigest components should happen gradually $[8,11,12]$.

In the second phase (5 - 13 weeks for heavy type turkeys and 9-13 weeks for medium type turkeys), grower feed is used. This period is characterized by intensive development of the skeleton and muscles of the bird. It is necessary for the bird to consume feed without any restriction and have the highest possible increase in live weight.

Table 2 - Norms of nutrient content in mixed feeds for heavy type turkeys

\begin{tabular}{|c|c|c|c|c|c|c|c|}
\hline \multirow[t]{2}{*}{ Nutrients } & \multicolumn{4}{|c|}{ Young age, weeks } & \multirow{2}{*}{$\begin{array}{c}\text { Turkeys- } \\
\text { producers }\end{array}$} & \multicolumn{2}{|c|}{ Laying turkeys, weeks } \\
\hline & "1-4 & "5-13 & 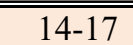 & $218-30^{*}$ & & (31-44 & "45-54 \\
\hline $\begin{array}{l}\text { Exchange energy in } 100 \mathrm{~g} \text { : } \\
\text { kcal } \\
\text { kJ }\end{array}$ & $\begin{array}{l}290 \\
1214\end{array}$ & $\begin{array}{l}300 \\
1260\end{array}$ & $\begin{array}{l}300 \\
1260\end{array}$ & $\begin{array}{l}270 \\
1130\end{array}$ & $\begin{array}{l}280 \\
1172\end{array}$ & \begin{tabular}{|l}
290 \\
1214
\end{tabular} & $\begin{array}{l}280 \\
1172\end{array}$ \\
\hline C Crude protein, $\%$ & 28 & 22 & 20 & 14 & 16 & 17 & 15 \\
\hline Crude fiber, $\%$ & 4,0 & $\overline{5,0}$ & 6,0 & 7,0 & 5,5 & 5,5 & 5,5 \\
\hline Calcium, $\%$ & $1 \overline{1,7}$ & 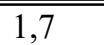 & 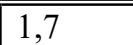 & $1,1,7$ & $1,1,5$ & 3,2 & 2,9 \\
\hline Phosphorus, $\%$ & 1,0 & 0,8 & 0,8 & 0,7 & 0,7 & 1,2 & 0,8 \\
\hline $\begin{array}{l}\text { Sodium, } \% \\
\end{array}$ & 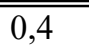 & 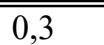 & 0,3 & 0,3 & 0,3 & 0,3 & 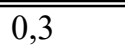 \\
\hline Lysine, $\%$ & 1,5 & 1,19 & 1,07 & 0,75 & 0,7 & 0,7 & 0,7 \\
\hline "Methionine, $\%$ & "0,60 & "0,47 & 0,43 & (0,30 & (0,32 & 0,32 & (20,32 \\
\hline Methionine + cystine, $\%$ & 1,0 & 0,79 & 0,71 & 0,50 & 0,57 & 0,57 & 0,57 \\
\hline "Tryptophan,\% & 0,27 & 0,21 & 0,19 & 0,14 & 0,15 & 0,15 & 0,15 \\
\hline "Arginine, $\%$ & 1,60 & 1,26 & 1,11 & 0,80 & 0,86 & 0,86 & 0,86 \\
\hline "Histidine, $\%$ & "0,60 & 0,47 & 0,43 & 0,30 & 0,32 & 0,32 & 0,32 \\
\hline Leucine, $\%$ & 1,90 & 1,50 & 1,36 & 0,95 & 1,20 & 1,20 & 1,20 \\
\hline Isoleucine, $\%$ & $1,1,03$ & 0,80 & 0,74 & 0,51 & 0,50 & 0,50 & 0,50 \\
\hline Phenylalanine, $\%$ & 1,00 & 0,79 & 0,71 & 0,50 & 0,50 & 0,55 & 0,55 \\
\hline Phenylalanine + tyrosine, $\%$ & $1,1,80$ & 1,42 & 1,28 & 0,90 & 0,88 & 0,88 & 0,88 \\
\hline Threonine, $\%$ & 1,00 & 0,79 & 0,71 & 0,50 & 0,40 & 0,40 & 0,40 \\
\hline "Valine, $\%$ & 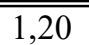 & (20,94 & 0,85 & (20,60 & (20,70 & 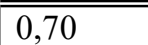 & "0,70 \\
\hline Glycine, $\%$ & 1,10 & 0,86 & 0,79 & 0,55 & 0,74 & 0,74 & 0,74 \\
\hline
\end{tabular}

Note. * Repair young turkeys and fattened males up to 23 weeks old 
Table 3 - Norms of nutrient content in mixed feeds for medium type turkeys

\begin{tabular}{|c|c|c|c|c|c|c|c|}
\hline \multirow[t]{2}{*}{ Nutrients } & \multicolumn{4}{|c|}{ Young age, weeks } & \multirow{2}{*}{$\begin{array}{l}\text { Turkeys- } \\
\text { producers }\end{array}$} & \multicolumn{2}{|c|}{ Laying turkeys, weeks } \\
\hline & $1-4$ & $5-13$ & $14-17$ & $18-30^{*}$ & & $31-44$ & $45-54$ \\
\hline $\begin{array}{l}\text { Exchange energy in } 100 \mathrm{~g} \text { : } \\
\text { kcal } \\
\mathrm{kJ}\end{array}$ & $\begin{array}{c}285 \\
1193\end{array}$ & $\begin{array}{c}290 \\
1214\end{array}$ & $\begin{array}{c}290 \\
1214\end{array}$ & $\begin{array}{c}275 \\
1115\end{array}$ & $\begin{array}{c}280 \\
1172\end{array}$ & $\begin{array}{c}290 \\
1214\end{array}$ & $\begin{array}{c}280 \\
1172\end{array}$ \\
\hline Crude protein, \% & 28 & 22 & 20 & 14 & 16 & 16 & 15 \\
\hline Crude fiber, $\%$ & 5,5 & 5,5 & 6,0 & 7,0 & 5,5 & 5,5 & 5,5 \\
\hline Calcium, $\%$ & 1,7 & 1,8 & 1,8 & 1,8 & 1,5 & 3,2 & 2,9 \\
\hline Phosphorus, \% & 1,0 & 0,8 & 0,8 & 0,8 & 0,7 & 1,2 & 0,8 \\
\hline Sodium, $\%$ & 0,4 & 0,4 & 0,4 & 0,4 & 0,3 & 0,4 & 0,4 \\
\hline Lysine, $\%$ & 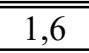 & $1,1,2$ & 0,97 & 0,61 & 0,7 & 0,69 & 0,69 \\
\hline Methionine, $\%$ & - & - & - & - & 0,32 & 0,27 & 0,27 \\
\hline Methionine + cystine, $\%$ & 0,97 & 0,81 & 0,65 & 0,41 & 0,57 & 0,43 & 0,43 \\
\hline Tryptophan,\% & 0,28 & 0,23 & 0,20 & 0,16 & 0,15 & 0,15 & 0,15 \\
\hline Arginine, $\%$ & 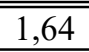 & $1,1,26$ & 1,07 & 0,65 & 0,86 & 0,73 & 0,73 \\
\hline Histidine, $\%$ & 0,53 & 0,44 & 0,39 & 0,29 & 0,32 & 0,30 & 0,30 \\
\hline Leucine, $\%$ & $1,1,86$ & 1,49 & 1,46 & 1,18 & 1,20 & 1,03 & 1,03 \\
\hline Isoleucine, $\%$ & 1,18 & 0,97 & 0,87 & 0,61 & 0,50 & 0,65 & 0,65 \\
\hline Phenylalanine, $\%$ & 1,18 & 0,97 & 0,86 & 0,63 & 0,55 & 0,67 & 0,67 \\
\hline Phenylalanine + tyrosine, $\%$ & 1,94 & 1,62 & 1,46 & 1,09 & 0,88 & 1,05 & 1,05 \\
\hline Threonine, $\%$ & 0,97 & 0,78 & 0,71 & 0,49 & 0,40 & 0,53 & 0,53 \\
\hline Valine, $\%$ & 1,30 & 1,04 & 0,93 & 0,72 & 0,70 & 0,72 & 0,72 \\
\hline Glycine, $\%$ & 1,26 & 0,94 & 0,84 & 0,58 & 0,74 & 0,62 & 0,62 \\
\hline
\end{tabular}

Note. * Diet of turkeys up to 17 weeks of age is recommended to be fed according to the standards for meat young

Table 4 - Nutritional value of mixed feeds according the feeding program for turkeys

\begin{tabular}{|c|c|c|c|c|c|c|c|c|c|c|}
\hline \multirow[t]{2}{*}{ Nutrients } & \multicolumn{5}{|c|}{ Heavy type turkeys } & \multicolumn{5}{|c|}{ Medium type turkeys } \\
\hline & 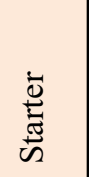 & $\begin{array}{l}\overline{0} \\
\text { 亏े } \\
\dot{0}\end{array}$ & 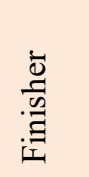 & 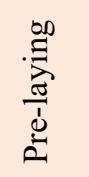 & 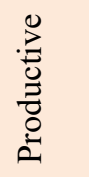 & 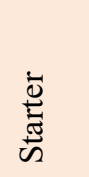 & $\begin{array}{l}\overline{0} \\
\text { oे } \\
\dot{0}\end{array}$ & 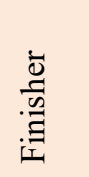 & 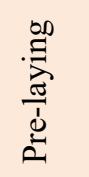 & 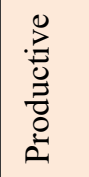 \\
\hline Exchange energy kcal/100 g & 290 & 300 & 300 & 270 & 280 & 285 & 290 & 290 & 275 & 280 \\
\hline Crude protein, $\%$ & 28 & 22 & 20 & 14 & 16 & 25 & 20 & 18 & 13 & 14 \\
\hline Linoleic acid C18:2 $\omega 6$ & 1,5 & $1,1,5$ & 1,8 & 2,0 & 1,5 & 1,5 & 1,5 & 1,8 & 2,0 & $1, \overline{1,5}$ \\
\hline Crude fiber, no more, $\%$ & 4,0 & 5,0 & 6,0 & $7,7,0$ & 6,0 & 5,5 & 5,5 & $7 \overline{7,0}$ & $7,7,0$ & $7,7,0$ \\
\hline Lysine, $\%$ & 1,50 & 1,19 & $1,1,07$ & 0,75 & 0,70 & 1,60 & 1,20 & 0,97 & 0,61 & 0,69 \\
\hline Methionine, $\%$ & 0,60 & 0,47 & 0,43 & 0,30 & 0,32 & 0,55 & 0,46 & 0,37 & 0,23 & 0,27 \\
\hline Methionine + cystine, $\%$ & 1,00 & 0,79 & 0,71 & 0,50 & 0,57 & 0,97 & 0,81 & 0,65 & 0,41 & 0,48 \\
\hline Threonine, $\%$ & 1,00 & 0,79 & 0,71 & 0,50 & 0,40 & 0,97 & 0,78 & $0,0,71$ & 0,49 & 0,53 \\
\hline Tryptophan,\% & 0,27 & 0,21 & 0,19 & 0,14 & 0,15 & 0,28 & 0,23 & 0,20 & 0,16 & 0,15 \\
\hline Arginine, $\%$ & $1,1,6$ & 1,26 & $1,1,11$ & 0,80 & 0,86 & $1,1,64$ & 1,26 & 1,07 & 0,65 & 0,73 \\
\hline Isoleucine, $\%$ & 1,03 & 0,80 & 0,74 & 0,51 & 0,50 & 1,18 & 0,97 & 0,87 & 0,61 & 0,65 \\
\hline Leucine, $\%$ & 1,90 & $1,1,50$ & 1,36 & 0,95 & 1,20 & 1,86 & $1,1,49$ & 1,46 & 1,18 & 1,03 \\
\hline Valine, $\%$ & 1,20 & 0,94 & 0,85 & 0,60 & 0,70 & 1,30 & $1,1,04$ & 0,93 & 0,72 & 0,72 \\
\hline "Histidine, $\%$ & 0,60 & 0,47 & 0,43 & 0,30 & 0,32 & 0,53 & 0,44 & 0,39 & 0,29 & 0,30 \\
\hline Phenylalanine,\% & 1,00 & 0,79 & 0,71 & 0,50 & 0,55 & 1,18 & 0,97 & 0,86 & 0,63 & 0,67 \\
\hline Phenylalanine + tyrosine, $\%$ & 1,80 & 1,42 & 1,28 & 0,90 & 0,88 & 1,94 & 1,62 & 1,46 & 1,09 & 1,05 \\
\hline "Glycine, $\%$ & 1,10 & 0,86 & 0,79 & 0,55 & 0,74 & 1,26 & 0,94 & 0,84 & 0,58 & 0,62 \\
\hline Calcium, $\%$ & 1,70 & 1,70 & 1,70 & 1,70 & 2,80 & 1,70 & 1,80 & 1,80 & 1,80 & 2,50 \\
\hline Phosphorus, $\%$ & $1,1,00$ & 0,80 & 0,80 & 0,70 & $\begin{array}{ll}0,70 \\
\end{array}$ & $\begin{array}{ll}1,00 \\
\end{array}$ & $0,0,80$ & 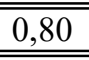 & 0,80 & 0,80 \\
\hline Sodium, $\%$ & 0,40 & 0,30 & 0,30 & 0,30 & 0,30 & 0,40 & 0,40 & 0,40 & 0,40 & 0,40 \\
\hline
\end{tabular}


In the third phase (14 - 17 weeks) finisher feed is used. This is the so-called "slow development", the intensity of growth during this period decreases, the reproductive organs are developing very rapidly. It is important during this period not to be overweight in the bird. Finisher feed has a more moderate level of nutrients, which has a positive effect on the development of feed intake. The basis of good poultry productivity is standard live weight and good development. At this time the turkey is fed to the top of her bent, with synchronous constant control of body weight.

For 2 - 3 weeks before slaughter turkeys the content of fish meal in the diet is reduced to $3-5 \%$ or completely exclude, replacing other protein feeds. Stabilized feed fat is used to improve the quality of the carcasses. When using high-calorie diets $(300 \mathrm{kcal}$ in $100 \mathrm{~g}$ of feed) for fattening turkeys, the norm of vitamin $E$ is increased.

From the 18th week turkeys are transferred to pre-laying diet. It is also advisable to increase energy and amino acids as they promote ovary and oviduct. During this period a strict differentiation of the nutritional rations is required, depending on the type of turkey.

From the 31th week turkeys are transferred to productive diet. It is necessary to increase the calcium content about twice compared to mixed feed for the young turkeys, since during this period the body produces hormones that contribute to its accumulation in the skeleton. Differentiated annular feeding of laying turkeys is recommended for the purpose of obtaining complete hatching eggs. In the morning the turkeys receive a feed containing $1 / 3$ of the daily rate of calcium, in the afternoon - the rest.

It is necessary to constantly monitor the live weight and egg production of turkeys in order to timely adjust the diets. In the case of premature oviposition or low live weight of the bird, the protein level in the diet should be increased.

The energy and protein levels are the same for breeding turkeys as for females, but they need to increase the level of animal feed by $2-3 \%$ and reduce the calcium content by $1,5 \%$, since a higher level of it reduces egg fertilization. Particular attention is paid to the balance of arginine, which plays an important role in sperm formation. Norms of fat-soluble vitamins (A, D, E) should be increased in 2 - 3 times in comparison with norms for layers, and vitamin $\mathrm{C}$ is given at the rate of $100 \mathrm{~g}$ per 1 ton of feed.

If the live weight and productivity of turkeys are high, they are well supplied with vitamins, macro- and trace elements, then they can be transferred to limited feeding (by 15\%), which provides significant savings of feed without sacrificing poultry $[4,9]$.

\section{Conclusions}

Thus, the turkey farming business is considered investment attractive because of its high profitability, ease of breeding and keeping poultry, low level of competition in the producer market, especially in Ukraine. There are two turkey breeds used in Ukraine and obtained from crossbreeding high-performance imported crosses that differ in productivity, destination and feed conversion. The analysis of the classification of modern turkeys breeds and crosses makes it possible to get the maximum profit from growing, subject to the appropriate conditions of keeping and feeding.

A high level of productivity and the associated level of feed conversion in turkey farming can be achieved only through high-quality keeping and use of high-quality, well-balanced and high-protein diets comprising easily digestible and properly prepared feed components.

We developed turkey feeding programs based on years of experience, scientific achievements in the industry and fruitful collaboration with feed manufacturers. There are several periods during the life of the turkeys: the period of rearing, pre-laying (rearing of the repair young turkeys) and productive.

REFERENCES

[Veb-sayt]. Odesa, 2019.

$U R L:$ http://agroportal.ua/publishing/analitika/alternativa-na-indyushinom-biznese (data obrashcheniya: 22.03.2019).

2. Indyuki snova rentabel ny: razrabotan biznes-plan proizvodstva v Ukraine indyushinoho myasa // INFORMATSIONNDIY DAYDZhEST \&quot; ANALITIKA I FINANSbI\&quot;: [Veb-sayt]. Odesa, 2019. URL: https://proconsulting.ua/pressroom/indyuki-snova-rentabelny-razrabotan-biznes-plan-proizvodstva-v-ukraine-indyushinogo-myasa (data obrashcheniya: 22.03.2019).

3. Mikhaylenko V. // analiz ukrainskoho rynka kombikormov. Odesa, 2018. URL: http://www.apnua.com/demo/archive/2010_an115_korm_demo.pdf(data obrashcheniya: 16.10.2018).

4. Lemesheva M.M. Kormlenie sel 'skokhozyaystvennoy ptitsy: monohrafiya. Sumy: Slobozhanshchina, 2003. 152 s.

5. Pernat'ev Yu.S. Razvedenie i vyrashchivanie indyukov, perepelov i tsesarok monohrafiya. Khar'kov: Klub semeynoho dosuha, 2017. $200 \mathrm{~s}$.

6. Mel nik V.O. Suchasni porodi i krosi indikiv // derzhavna doslidna stantsiya ptakhivnitstva NAAN. Odesa, 2019. URL: http://avianua.com/ua/index.php/statty_po_pticevodstvu/tekhnolohiia-ptakhivnytstva/31-porody_i_krocy_indykiv

(data zvernennya: 22.05.2019)

7. Dzitsyuk V.V. Porodi, liniyi ta krosi indikiv // ahrarniy sektor Ukrayini. Odesa, 2019. URL: http://agroua.net/animals/catalog/ag-10/a-13/info/aig-82/(data zvernennya: 22.05.2019).

8. Svezhentsev A.I., Urdzik R.M., Ehorov I.A. Korma i kormlenie sel skokhozyaystvennoy ptitsy: monohrafiya. Dnepropetrovsk: ART-PRESS, 2006. $380 \mathrm{~s}$

9. Svezhentsev A.I. Prohrammy normirovannoho kormleniya ptitsy: spravochno-metodicheskoe rukovodstvo. Dnepropetrovsk: ART-PRESS, 1999. $250 \mathrm{~s}$

10. Yehorov B.V., Hontsa N.V. Analiz suchasnikh prohram hodivli molodnyaka kurey-nesuchok // Zernovi produkti i kombikormi. 2009. T. 1, vip. 4. S. 49-51.

11. Kryukov V., Baykovskaya E. Kormlenie tsyplyat v pervye dni zhizni // Kombikorma. 2001. T. 1, vyp. 8. S. 55

12. Ivleva D.S. Vsehda uchityvay fiziolohicheskie protsessy, proiskhodyashchie v orhanizme ptitsy // Tvarinnitstvo s'ohodni. 2010. T. 1, vyp. 3. S. 72-75. 
А.В. Макаринська, канд. техн. наук, доцент, E-mail: allavm2015@gmail.com Н.В. Ворона, канд. техн. наук, доцент, E-mail: tarnin@te.net.ua Кафедра технології комбікормів і біопалива, Одеська національна академія харчових технологій, вул. Канатна, 112, Одеса, 65039, Украӥна

\section{ОСОБЛИВОСТІ ВИРОЩУВАННЯ ТА АНАЛІЗ ПРОГРАМ ГОДІВЛІ ІНДИКІВ}

\section{Анотація}

У статті зазначено, що відповідно до літературного огляду у структурі м'ясного ринку птахівництво займає лідируючі позиції. Лідером у птахівництві, як у світі, так і в Україні, є виробництво м'яса бройлерів. Однак в останні роки різко підвищився інтерес до індиківництва, як галузі прибуткового бізнесу, та м'яса індиків, як альтернативи свинини та яловичини. Встановлено, що споживання м'яса індичок у світі за останні роки збільшилось з 1,5 млн. $m$ до 5,5 млн. Лідером у світі з річного споживання індичого м'яса є Ізраїль (13,1 кг на душу населення), а з виробництва - США (42\% від загального обсягу виробництва). Об' $є м$ виробництва м'яса індиків у світі у 2017 ройі склав 6,4 млн. $m$, з них в Україні було вироблено тільки 34 тис. т.

Наведені основні характеристики двох порід індиків, від яких пішли майже всі сучасні промислові кроси індиків ие бронзова широкогруда та біла широкогруда породи. Усі високопродуктивні кроси індиків поділяють на типи в залежності від ваги: легкий, середній, середньоважкий, важкий. Кожен із них має своє призначення для використання.

В результаті аналізу літературних даних були узагальнені показники продуктивності сучасних кросів індиків та норми вмісту поживних та біологічно активних речовин у комбікормах для індиків важкого та середнього типів.

На підставі багаторічного досвіду, наукових досягнень в галузі і плідної сумісної роботи з виробниками комбікормової продукції нами були розроблені програми годівлі індиків. Розрізняють декілька періодів впродовж життя індиків: період вирощування молодняка, передкладковий (вирощування ремонтного молодняка) та продуктивний.

Встановлено, що молодняк індиків різного призначення годують однаковими раџіонами до 17 тижня. За розробленою програмою годівлі індиків період вирощування складається з трьох фаз, впродовж яких використовують стартовий (1 - 4 тижні для індиків важкого типу та 1 - 8 тижнів для індиків середнього типу), гроуерний (5 - 13 тижнів для індиків важкого типу та 9 - 13 тижнів для індиків середнього типу) та фінішний (14 - 17 тижнів) комбікорми. Передкладковий раціон згодовують з 18 до 30 тижня ремонтному молодняку, а продуктивний - з 31 тижня.

Ключові слова: індики, технологія годівлі, програма годівлі, вимоги до поживності комбікормів для індиків, породи та кроси індиків

\section{ЛIТЕРАТУРА}

1. Альтернатива на индюшином бизнесе // Аналитика: [Веб-сайт]. Одеса, 2019. URL: http://agroportal.ua/publishing/analitika/alternativa-na-indyushinom-biznese (дата обращения: 22.03.2019).

2. Индюки снова рентабельны: разработан бизнес-план производства в Украине индюшиного мяса // ИНФОРМАЦИОННЫЙ ДАЙДЖЕСТ \&quot;АНАЛИТИКА И ФИНАНСЫ\&quot;: [Веб-сaйm]. Odeca, 2019. URL: https://pro-consulting.ua/pressroom/indyuki-snova-rentabelny-razrabotan-biznes-plan-proizvodstva-v-ukraineindyushinogo-myasa (дата обращения: 22.03.2019).

3. Михайленко В. // Анализ украинского рынка комбикормов. Одеса, $2018 . \quad$ URL: http://www.apnua.com/demo/archive/2010__an115_korm_deто.pdf(дата обращения: 16.10.2018).

4. Лемешева М.М. Кормление сельскохозяйственной птииь: монография. Сумы: Слобожанщина, 2003. $152 \mathrm{c}$.

5. Пернатьев Ю.С. Разведение и выращивание индюков, перепелов и цесарок: монография. Харьков: Клуб семейного досуга, 2017. 200 c.

6. Мельник В.О. Сучасні породи і кроси індиків // державна дослідна станиія птахівниитва НААН. Одеса, 2019. URL: http://avianua.com/ua/index.php/statty_po pticevodstvu/tekhnolohiia-ptakhivnytstva/31porody_i_krocy_indykiv (дата звернення: 22.05.2019).

7. Дзічюк В.В. Породи, лінії та кроси індиків // аграрний сектор України. Одеса, 2019. URL: http://agroua.net/animals/catalog/ag-10/a-13/info/aig-82/ (дата звернення: 22.05.2019).

8. Свеженщев А.И., Урдзик Р.М., Егоров И.А. Корма и кормление сельскохозяйственной птиць: монография. Днепропетровск: АРТ-ПРЕСС, 2006. 380 c.

9. Свеженщев А.И. Программы нормированного кормления птищы: справочно-методическое руководство. Днепропетровск: АРТ-ПРЕСС, 1999. 250 с.

10. Сгоров Б.В., Гонща Н.В. Аналіз сучасних програм годівлі молодняка курей-несучок // Зернові продукти $і$ комбікорми. 2009. T. 1, вип. 4. С. 49-51.

11. Крюков В., Байковская Е. Кормление йыплят в первые дни жизни // Комбикорма. 2001. T. 1, вып. 8. С. 55.

12. Ивлева Д.С. Всегда учитывай физиологические процессы, происходящие в организме птищы // Твариннищтво сьогодні. 2010. T. 1, вып. 3. C. 72-75.

Received 19.06.2019.

Reviewed 12.07.2019

\section{Revised 28.08.2019}

Approved 03.09.2019.

Cite as Vancouver Citation Style

Makarynska A., Vorona N. Peculiarities of growing and analysis of feeding programs for turkeys. Grain Products and Mixed Fodder's, 2019; 19 (3): 27-33. DOI: https://doi.org/

Cite as State Standard of Ukraine 8302:2015

Peculiarities of growing and analysis of feeding programs for turkeys / Makarynska A. et al. // Grain Products and Mixed Fodder's. 2019. Vol. 19, Issue 3. P. 27-33. DOI: https://doi.org/

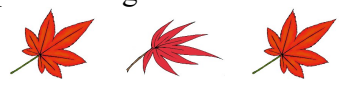

